\title{
Estudo in silico de benzimidazois utilizados em agricultura em relação a aspectos medicinais
}

Paulo H. Peruquetti ${ }^{1}(\mathrm{PG})^{{ }^{*}}$, Aline T. Bruni ${ }^{1}(\mathrm{PQ})$.

paulo.peruquetti@usp.br

${ }^{1}$ Departamento de Química, FFCLRP, Universidade de São Paulo

Palavras-chave: Benzimidazol, Pesticidas, QSAR, Docking

O Brasil, por ser um país agrícola, é um grande consumidor de pesticidas. Recentemente, foi proposto o projeto de lei PL3200/15, que tem por objetivo promover uma flexibilização da atual lei de agrotóxicos, permitindo a utilização de compostos antes proibidos e facilitando ainda mais o uso daqueles permitidos. Com a maior abrangência da lei é de extrema importância desenvolver métodos rápidos, eficazes e reprodutíveis para que seja possível estudar os riscos e os efeitos que as substâncias utilizadas na agricultura podem ter no ser humano e outros ecossistemas. A determinação de doses letais e outros aspectos toxicológicos desses compostos são de grande interesse para a prevenção e gestão dos danos que podem vir a ser ocasionados pelo mal-uso dos defensivos agrícolas. Contudo, os estudos in vivo ou in vitro são caros, demandam tempo e muitas vezes não são reprodutíveis. Como uma alternativa a esses testes clássicos temse a toxicologia in silico, que por meio de descritores físico-químicos, estabelece relações com diversas propriedades toxicológicas substâncias. Os métodos in silico possibilitam o estudo de uma grande quantidade de substâncias em um curto período de tempo, além de dispensar os testes em organismos vivos por conseguir mimetizá-los, tornando-o um método extremamente reprodutível. Dessa forma, o objetivo principal desse trabalho foi avaliar a dose letal aguda para 50\% de uma população de ratos, DL50, por meio de vários softwares livres e assim, desenvolver um modelo confiável e robusto de determinação da $\mathrm{DL}_{50}$ de pesticidas.

Os grupos de moléculas estudadas foram um grupo de herbicidas benzimidazólicos derivados do 2-trifluormetilbenzimidazol e um grupo de fármacos, também benzimidazois, que apresentam atividade anti-HIV1. Foram utilizados programas livres para calcular a DL $_{50}$ das moléculas do grupo de pesticidas, comparando com o valor experimental. Métodos ab-initio de química computacional para obter descritores físico-químicos para ambos os grupos, e por meio de técnicas quimiométricas foi desenvolvido um modelo quantitativo de relação atividade-estrutura, QSAR, para verificação do mecanismo de ação dessas substâncias e de outras que possam vir a ser sintetizadas. Por fim, um estudo preliminar de docking foi realizado com o intuito de 
avaliar a possibilidade de os herbicidas poderem atuar como medicamentos e vice-versa, dentre outras possibilidades.

Os resultados obtidos até o momento mostraram que os valores de $\mathrm{DL}_{50}$ provenientes dos softwares livres foram comparáveis com os valores experimentais, mostrando reprodutibilidade de comportamentos. Comparando os valores de $\mathrm{DL}_{50}$ originados pelos softwares foi possível averiguar qual melhor descrevia o grupo de moléculas em questão. Dentre todos os utilizados o Pro-Tox II foi o que obteve melhores resultados nos cálculos das DL50. Para a avaliação QSAR o método quimiométrico PLS foi utilizado para a validação do modelo e determinação do seu domínio de aplicabilidade. $\mathrm{Na}$ avaliação de docking, o modelo faz uma predição da interação entre a molécula estudada e o receptor em questão e, por meio de valores de forças de interação, mostrando uma tendência da intensidade entre o pesticida e o sítio de ação no organismo, como visto em drogas ilícitas. Dados obtidos na literatura foram utilizados de maneira comparativa para embasar a relevância e a possibilidade da atuação de cada grupo como herbicida ou medicamento.

Agredecimento: ao CNPQ pelo apoio relacionado à bolsa de estudos para a realização desse projeto.

\section{REFERÊNCIAS}

1. Adamson, G. W., Bawden, D., Saggers, D. T. Quantitative Structure-Activity Relationship Studies of Acute Toxicity $\left(\mathrm{LD}_{50}\right)$ in a Large Series of Herbicidal Benzimidazoles. Pestic Sci, 1984, v. 15: 31-39. DOI: $10.1002 /$ ps.2780150106

2. Folgado, C. A. R. Sistema Normativo De Agrotóxicos Na Contemporaneidade. Revista Jurídica da Universidade Estadual de Feira de Santana, 2016, v. 1, n. 1. DOI: http://dx.doi.org/10.12102/rjuefs.v1i1.1819

3. Lagos, C. F., Caballero, J., Gonzalez-Nilo, F. D., Pessoa-Mahana, C. D., Perez-Acle, T. Docking and Quantitative Structure-Activity Relationship Studies for the Bisphenylbenzimidazole Family of NonNucleoside Inhibitors of HIV-1 Reverse Transcriptase. Chemical Biology and Drug Design, 2008, v. 72: 360-369. DOI: $10.1111 / \mathrm{j} .1747-0285.2008 .00716 . \mathrm{x}$ 